\title{
Microstructural Coarsening of Semi-Solid Aluminium Alloys
}

\author{
H. V. Atkinson and D. Liu* \\ Department of Engineering, University of Leicester, University Road, Leicester LE1 7RH, UK \\ Now with Wolfson Microelectronics PLC., 26, Westfield Rd., Edinburgh, EH11 2QB, UK.
}

\begin{abstract}
Semisolid metal processing involves processing metallic alloys between the solidus and the liquidus. The microstructure must be non-dendritic and consist of spheroids of solid in a liquid matrix. Two potential routes to suitable starting material are recrystallisation and partial melting (RAP) and cooling slope (CS). Here the microstructural coarsening of such materials in the semi-solid state is compared with rates in the literature.
\end{abstract}

A slightly lower coarsening rate was observed for RAP route 2014 alloy with $37 \%$ fraction liquid than for CS route 2014 alloy with 17\% fraction liquid despite the higher fraction liquid for the former. For the CS route, an increase in fraction liquid gave a higher coarsening rate. A relatively high coarsening rate was observed in a modified 2014 alloy with the Fe, Mn and $\mathrm{Zn}$ stripped out of the composition and a relatively low Si content. The coarsening rate was also relatively high for alloy 201 prepared by the CS route compared with alloy 2014 either by RAP or CS. It is likely that relatively low coarsening rates are associated with the presence of particles which are inhibiting the migration of liquid film grain boundaries, either through a pinning mechanism or through impeding diffusion through the liquid film at the boundary.

Keywords: semi-solid, alloys 2014 and 201, spheroidal microstructure, coarsening.

\section{Introduction}

Semi-solid metal processing is a near net shape manufacturing process for metals and alloys, which takes place at temperatures between the solidus and the liquidus. Several reviews are available [1-5]. Components produced by semi-solid processing have higher mechanical properties and reduced porosity compared with conventional casting. The process depends on the material behaving in a thixotropic way in the semisolid state i.e. flowing when sheared but thickening again when allowed to stand. This behaviour requires the microstructure to consist 
of spheroids of solid surrounded by a liquid matrix. When sheared, the bonds between the spheroids break down. On standing the spheroids reagglomerate.

Thixoforming is one branch of semi-solid processing. Feedstock material is prepared which, when it is heated into the semisolid state, gives a spheroidal microstructure. Thixoforming involves feedstock material which is initially in the solid state, in contrast with rheocasting where the spheroidal microstructure is obtained during the process without a solidification step eg. by stirring during cooling from the liquid into the semisolid region. The preparation of the feedstock material for thixoforming introduces extra cost in comparison with casting. There is therefore a drive to develop simple and effective routes to produce thixotropic materials. The rate of microstructural evolution in the semi-solid state during reheating then determines whether a material is suitable; extensive coarsening will have a deleterious effect on final mechanical properties.

In this paper, two routes were used to produce thixotropic material - recrystallisation and partial melting (RAP) [6] and cooling slope casting (CS) [7]. The former has already been used commercially for the production of components, the latter is part of the process called New Rheocasting (NRC) [8,9] and indeed has wider potential applications [e.g. 10,11]. In the RAP route, material which has been worked, for example by extrusion, at temperatures below the recrystallisation temperature, is then reheated into the semisolid state. Recrystallisation occurs and the first liquid to form tends to penetrate down the recrystallised boundaries, resulting in spheroids of solid in a liquid matrix, the ideal microstructure for thixoforming. The RAP route is allied to the Strain Induced Melt Activated (SIMA) route [12] but in the SIMA route working takes place 'hot', i.e. above the recrystallisation temperature, and is followed by a period of cold work prior to reheating. In RAP the working is warm (i.e. below the recrystallisation temperature). The advantages of the RAP route are that many aerospace alloys are supplied in the worked state and hence in a state ready for reheating and semisolid processing. In addition, the spheroids tend to be very well rounded in comparison with those produced by liquid state routes to thixoformable microstructures (for example, magnetohydrodynamic stirring) and hence give advantageous flow properties [13]. The main disadvantage is that wider diameter billets are difficult to work and there may be inhomogeneity in the degree of work introduced across the component, leading to inhomogeneous spheroidal microstructure across the cross-section. 
In the Cooling Slope route, liquid metal is poured onto a chilled slope. Copious nuclei are generated on the slope and a spheroidal structure can then be achieved in the mould. In the NRC process, the material is then fed directly to a shot sleeve without intermediate solidification hence saving energy and enabling waste to be recycled within the plant itself. Alternatively, the material in the mould can be solidified and then reheated for thixoforming. In this paper, microstructural coarsening of semi-solid alloys produced by this route and by the RAP route is analysed and compared with results from the literature. The rate of microstructural coarsening is important partly because semi-solid materials with a coarse grain size do not deform as easily as those with a fine grain size [14] and also because the mechanical properties of the product are degraded if the grain size is larger.

Classically, for low fractions of solid where the solid particles are well separated and noninteracting, the LSW theory applies [15-17]. The driving force for coarsening in the semisolid state is the reduction in interfacial free energy. The simple LSW analysis gives:

$$
\bar{d}^{3}-\bar{d}_{0}^{3}=K t
$$

where $\bar{d}$ is the average particle diameter at time $t, \bar{d}_{0}$ is the average particle diameter at time $t=0$ and $K$ is the coarsening rate constant. For higher fractions of solid where the particle diffusion fields are interacting, Annavarapu and Doherty [18] proposed the liquid film migration model. With this model the coarsening rate should increase as fraction solid increases. However, experimental results [e.g. 19] for high fraction solid systems $\left(f_{s}>\sim 0.7\right)$ show a decreasing coarsening rate with increasing fraction solid. Manson-Whitton et al. [19] therefore developed a modified liquid film migration model to take into account the necks between the contacting solid particles. The form of the equation is still essentially as in (1). The transition between the liquid film migration model due to Annavarapu and Doherty [18] and the modified liquid film migration model due to Manson Whitton et al. [19] occurs at $f_{s o} \sim 0.7$ for their experimental materials (spray-formed $\mathrm{Al}-4 \mathrm{Cu}$ and $\mathrm{AA} 2618$ alloys). Manson-Whitton et al. suggest the transition value $\left(f_{s o}\right)$ will depend on the dihedral angle between two solid grains in contact with liquid. If wetting is difficult (large dihedral angle) then the transition will occur at lower values of the fraction solid. Kim and Yoon [20] and Boettinger et al. [21] have observed that, at high $f_{s}$, coarsening in Mo-Ni-Fe and Al-Sn alloys is controlled by diffusion through the liquid rather than by the solid-solid contacts, and 
grain contacts tend to lead to a decrease in grain growth rates because of the reduced solid/liquid interfacial area. Manson-Whitton et al. [19] also discuss the inhibition of coarsening by particles present at the grain boundary liquid films in order to account for slower rates of coarsening in alloy AA2618 than in Al-4wt.\%Cu alloy. They propose two possible explanations for the sharp increase in coarsening rate for AA2618 when the fraction of solid decreases from 0.75 to 0.7 . Firstly, $\mathrm{Al}_{9} \mathrm{FeNi}$ particles at the grain boundaries may be dissolving or melting on heating to the slightly higher temperature required for lower $f_{s}$, thus unpinning the liquid film. Secondly, for $f_{s}<0.75$, the $\mathrm{Al}_{9} \mathrm{FeNi}$ particles are becoming small relative to the thickness of the liquid film and hence ineffective as pinning particles. De Freitas et al. [22] have compared coarsening in alloy 2024 with Al-4wt.\%Cu in the semisolid state and also discussed the retarding effect that intermetallics exert on particle growth.

Grain coalescence is thought to play an important role. Tzimas and Zavaliangos [23] studied the evolution of near-equiaxed microstructures in the semi-solid state, produced by spray casting, magnetohydrodynamic (MHD) casting and the stress induced, melt activated (SIMA) process. Ostwald ripening and grain coalescence were thought to operate simultaneously and independently as soon as liquid is formed. Tzimas and Zavaliangos expected Ostwald ripening to be dominant at longer times and at high volume fractions of liquid, while growth by coalescence by grain boundary migration is dominant at short times after liquid is formed, at low volume fractions of liquid.

Here we analyse coarsening in the semi-solid state for four different materials which when reheated into the semisolid state will have spheroidal microstructures: 2014 (a conventionally wrought alloy) produced by the RAP route; 2014 produced by the cooling slope route; a modified 2014 (without the minor elements Fe, Mn and Zn and with relatively low silicon content) produced by the cooling slope route; and alloy 201 (a high strength casting alloy) produced by the cooling slope route. The composition of alloy 201 is quite close to 2014 but its strength derives from the presence of silver, which is not present in the other alloys. The alloys have previously been thixoformed and the results presented [24, 25]. The results will be compared with those for other cast and wrought alloys from the literature.

\section{Experimental procedure}


The condition of starting materials is summarised in Table 1. The extruded 2014 was used for both the RAP route and for remelting for the cooling slope route. The modified 2014 and the 201 were both treated with the cooling slope.

The liquid fraction-temperature relationship was determined using differential scanning calorimetry (DSC). Samples of about $3 \mathrm{~mm}$ diameter and $15 \mathrm{mg}$ weight were cut, weighed and put into carbon pans with carbon lids in an argon atmosphere. The DSC tests were carried out using a Dupont 910 Differential Scanning Calorimeter. The samples were heated to $680^{\circ} \mathrm{C}$ at $10 \mathrm{~K} / \mathrm{min}$ and cooled to room temperature at the same rate. The heat flow and temperature were monitored by thermocouples to obtain heating and cooling curves. The fraction liquid vs. temperature curves were obtained by integrating under the curves.

In the cooling slope casting route, as-received materials (as-extruded plus T6 2014, DC-cast modified 2014 and DC-cast 201) were melted in a bonded alumina crucible in an induction furnace and then cooled to $10 \sim 20 \mathrm{~K}$ above the liquidus temperature. This was followed by bottom pouring from the crucible onto a water-cooled slope and hence into a steel mould (50 $\mathrm{mm}$ in diameter and $150 \mathrm{~mm}$ in length). The mould was then quenched. A diagram of the cooling slope apparatus is given in [24] and further details in [26].

A salt bath furnace was used to study the microstructural evolution in the semisolid state. The temperatures were originally chosen to give fractions of liquid suitable for, or approaching those suitable for, thixoforming of each of the alloys concerned. It is therefore not the case that the same liquid fraction has been used for each alloy. Nevertheless useful data on coarsening coefficients for comparison with the literature can be obtained.

Samples with dimensions $8 \mathrm{~mm} \times 8 \mathrm{~mm} \times 15 \mathrm{~mm}$ were cut from wrought extruded bar and from ingots cast with the cooling slope. A hole of $1.6 \mathrm{~mm}$ was drilled into the centre of each sample in order to insert a thermocouple for monitoring the temperature of the samples. For the RAP route, as-received extruded 2014 in the T6 heat treated state was heated in a salt bath to $625^{\circ} \mathrm{C}$ and soaked for 3, 5, 10 and $30 \mathrm{~min}$ before water quenching. Temperatures of 610 and $620^{\circ} \mathrm{C}$ and soaking times of $1,3,5,10$ and 30 min were used for alloy 2014. A temperature of $631{ }^{\circ} \mathrm{C}$ was used for modified 2014 cooling slope ingot specimens and of $620^{\circ} \mathrm{C}$ for alloy 201 , with soaking times of 1,3 and $5 \mathrm{~min}$. The specimens were ground, polished and observed under an optical microscope and images taken. Quantitative 
measurements of the grain/rosette size $\left(d=(4 A / \pi)^{1 / 2}\right.$, where A is area of rosette) were carried out and the coarsening rate constants were calculated assuming the cubic power-law model (equation (1)). The term 'rosette' is used here to describe the microstructural features, which are generally not dendrites but are not fully rounded spheroids either. Some samples were examined with Scanning Electron Microscopy (SEM).

Micrograph sequences for the isothermal holding in the semisolid state for the conditions given for extruded 2014 in T6 temper, cooling slope modified 2014 and cooling slope alloy 201 have been presented in earlier work [24]. Here we focus on data for coarsening coefficients which has not previously been presented. We will present micrographs for cooling slope 2014. The previous work [24] has shown the condition of the starting material in each case. In the as-received extruded 2014, which is in the T6 heat treated condition, the grains are elongated in the extrusion direction. Some partially recrystallised grains were found located adjacent to coarse inclusions distributed longitudinally. The main intermetallic phases present were identified as $\mathrm{CuAl}_{2}$ and $(\mathrm{CuFeMn})_{3} \mathrm{Si}_{2} \mathrm{Al}_{15}$. The as-received $\mathrm{DC}$ cast 'modified' 2014 and alloy 201 consisted of dendritic $\alpha$-aluminium morphology with interdendritic eutectic. After cooling slope casting, the 'modified' 2014 is non-uniform, consisting of fine equiaxed dendrite cells in the centre of the ingot whilst the structure at the perimeter shows more features within the cells. The microstructure for the 201 cooling slope ingots is relatively uniform with fine equiaxed dendrite cells.

\section{Results}

\subsection{Liquid fraction versus temperature}

Curves for liquid fraction versus temperature derived from the DSC results are shown in Fig. 1. The corresponding liquid fractions for the temperatures chosen for isothermal holding of the specimens are shown in Table 2.

\subsection{Microstructural evolution during partial melting}


Fig. 2 shows as-cast cooling slope ingot microstructure for 2014 and the structural evolution during isothermal holding in the semisolid state at $610^{\circ} \mathrm{C}$ and $620^{\circ} \mathrm{C}$. Fine dendrites in the starting material transform into spheroids during the holding. Grain size measurement shows a continuous increase of grain size as the soaking time increases. Grain size increases from 53 to $61 \mu \mathrm{m}$ with increase in soaking time from 3 to $10 \mathrm{~min}$ at $610^{\circ} \mathrm{C}$ and from 51 to $84 \mu \mathrm{m}$ with increase in soaking time from 1 to $30 \mathrm{~min}$ at $620^{\circ} \mathrm{C}$. The error on the grain size measurement is $\pm 4 \mu \mathrm{m}$. Note that the liquid content apparent in the micrographs is not indicative of the quantity present at temperature because the quench is not sufficiently rapid for the liquid content to be entirely 'frozen in'. During the quench, some liquid deposits onto the solid, appearing to be 'solid' in the quenched microstructure [23]. The other alloys show similar microstructural development with time at temperature in the semisolid region (see [24]).

\subsection{Coarsening during partial melting}

Using the microstructural results for isothermal holding as presented in [24] and in section 3.2 above, the grain sizes were analysed using equation (1). Fig. 3 shows the evolution of the cube of the average globule diameter $\bar{d}^{3}$ as a function of isothermal soaking time in the semisolid state for alloy 2014, modified 2014 and alloy 201 with different initial microstructures. The intercept is the value of $\bar{d}_{0}^{3}$. The amounts of liquid present are not directly comparable. However, the following comments can be made. Slower coarsening kinetics were shown by alloy 2014 made by either CS or RAP routes: the values of coarsening rate constant $\mathrm{K}$ are $173 \mu \mathrm{m}^{3} \mathrm{~s}^{-1}$ for RAP 2014 held at $625^{\circ} \mathrm{C}$ with $37 \% \mathrm{f}_{\mathrm{L}}$, and $192 \mu \mathrm{m}^{3} \mathrm{~s}^{-1}$ and $255 \mu^{3} \mathrm{~s}^{-1}$ for $\mathrm{CS} 2014$ held at $610^{\circ} \mathrm{C}$ with $17 \% \mathrm{f}_{\mathrm{L}}$ and $620^{\circ} \mathrm{C}$ with $28 \% \mathrm{f}_{\mathrm{L}}$, respectively. Lower coarsening rate $\left(173 \mu \mathrm{m}^{3} \mathrm{~s}^{-1}\right.$ at $\left.625^{\circ} \mathrm{C}\right)$ was observed for the RAP route than for the CS route $\left(192 \mu \mathrm{m}^{3} \mathrm{~s}^{-1}\right.$ at $610^{\circ} \mathrm{C}$ and $255 \mu^{3} \mathrm{~s}^{-1}$ at $\left.620^{\circ} \mathrm{C}\right)$ and lower coarsening rate for the $\mathrm{CS}$ route at the lower heating temperature with lower fraction liquid. Compared with alloy 2014, relatively faster coarsening kinetics were shown by modified alloy 2014 and alloy 201 made by CS: the values of coarsening rate constant $\mathrm{K}$ are $1384 \mu^{3} \mathrm{~s}^{-1}$ for modified alloy 2014 held

at $631{ }^{\circ} \mathrm{C}$ with $45 \% \mathrm{f}_{\mathrm{L}}$ and $2157 \mathrm{\mu m}^{3} \mathrm{~s}^{-1}$ for alloy 201 held at $620^{\circ} \mathrm{C}$ with $20 \% \mathrm{f}_{\mathrm{L}}$. Here, more formally, the coarsening rate figures cannot be quoted to this precision and should be rounded to $170,190,260,1400$ and $2200 \mu \mathrm{m}^{3} \mathrm{~s}^{-1}$ respectively. 
Coarsening rate thus appears to be related to the initial microstructure, i.e. RAP or CS, and to the alloy composition. For example, for a similar initial microstructure from cooling slope casting, a higher coarsening rate constant was observed for modified alloy 2014 and alloy 201 than for unmodified alloy 2014.

\subsection{Liquid entrapped in the primary phase}

The microstructure presented in Fig. 4 shows clearly that some liquid pockets are present within the primary phase in modified alloy 2014 after soaking for $5 \mathrm{~min}$ at $631^{\circ} \mathrm{C}$. In grain $\mathrm{A}$, a large liquid droplet (indicated by arrow B) is apparently about to detach itself from the boundary and another one (indicated by arrow $\mathrm{C}$ ) is going to form from the liquid on the grain boundary. Note examples of liquid in the process of penetrating down boundaries.

\section{Discussion}

\subsection{Dendrite Arm Coalescence in the Early Stages for Cooling Slope Material}

Fine dendritic microstructures were obtained by CS casting with low superheating (see Fig. 2a). During partial melting and subsequent soaking in the semi-solid state, coarsening first proceeds predominantly through coalescence of dendrite arms (Fig. 4). As dendrite arms of the same grain have perfectly matching crystallographic orientations, this dendrite arm coalescence is expected to be extremely rapid. As long as the grains are not fully globular, coalescence will lead to an increase of the mean free path in the solid phase (i.e. an atom could diffuse further within a globule without encountering a barrier) but the number of grains will remain constant (i.e. no Ostwald ripening) until, eventually, the solid phase becomes globular [27]. After coalescence, phase coarsening will take place through the dissolution of the small globules and the grain number will then decrease [27].

In the alloys examined here, coalescence is having a relatively minor effect on the coarsening rate after the very initial stages. Comparing Fig. 2 (a) with Fig. 2 (b), for the very early stages of holding at $610^{\circ} \mathrm{C}$, essentially coalescence of the short dendrite arms in the equiaxed cells in the CS material has occurred by 3 min., giving globule sizes which are similar to the original cell sizes in the starting material. From that point, the mechanisms (and indeed coarsening 
rate) are very similar for CS 2014 and RAP 2014 (Fig. 3). This is consistent with the findings in $[23]$.

\subsection{Effects of Alloy Composition on Coarsening}

CS cast 2014 exhibits a lower coarsening rate constant $\left(192\right.$ and $255 \mu \mathrm{m}^{3} / \mathrm{s}$ at 610 and $\left.620^{\circ} \mathrm{C}\right)$ than CS cast modified $2014\left(1384 \mu \mathrm{m}^{3} / \mathrm{s}\right)$ and alloy $201\left(2157 \mu \mathrm{m}^{3} / \mathrm{s}\right)$. These alloys have similar copper contents (3.91, 3.87 and $4.35 \mathrm{wt} \%$ for alloy 2014, modified 2014 and 201, respectively). The significant difference in the coarsening rate constant must be attributed to the presence of secondary phases in alloy 2014. $\mathrm{CuAl}_{2}$ particles are responsible for the precipitation hardening capacity, tend to be sub-micron in size and will tend to dissolve below the solidus. In contrast, the insoluble Fe, Mn-containing particles will be present in the semisolid state and are of a size where they can potentially obstruct the migration of the liquid boundary, either through a pinning type mechanism or through inhibiting diffusion through the liquid from one boundary position to another [18]. The results are essentially consistent with the observations in [19-22] about the inhibiting effect of second phase particles. In modified alloy 2014, minor elements such as $\mathrm{Fe}, \mathrm{Mn}, \mathrm{Si}$, which form insoluble intermetallic phases, have been stripped out and the coarsening is much faster.

Fig. 5 shows a compilation of results from this work and from the literature, plotting coarsening coefficient against temperature. This is the most comprehensive collection of the data up until now. Fig. 6 is a magnified view of the $0-650 \times 10^{-18} \mathrm{~m}^{3} / \mathrm{s}$ range in $\mathrm{K}$ in Fig. 5 . There is a general trend for increase in $\mathrm{K}$ with increase in temperature in Fig. 6. However, scientifically $\mathrm{K}$ relates not only to temperature (since diffusion is faster at higher temperature) but also to fraction liquid (since liquid provides a much faster diffusion path than solid and once a continuous liquid path is present around the spheroids coarsening can accelerate). Fig. 7, therefore, plots the data for $\mathrm{Al}-4 \mathrm{Cu}$ alloys and $\mathrm{Al}-6.7 \mathrm{Cu}$ versus fraction liquid rather than temperature. Fig. 8 shows the coarsening coefficient for 2000 series alloys (and one 7000 series alloy) versus fraction liquid.

The majority of the results in Fig. 6 are for wrought composition alloys (AA2014, 2014, A2017, 2618, AA2618, 6061, 7075, AA7034) which are likely to have minority phase particles present (such as those based on Fe). The exceptions are circled. The AlCu4.5Mg1.5 
[18] (short solid blue lines) is DC-cast with a grain refiner. Annavarapu and Doherty [18] argue that the slow coarsening rate for this material is due to the Ti-rich grain refining

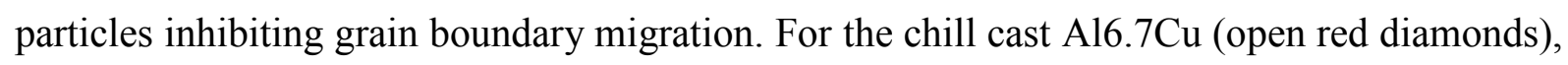
Annavarapu and Doherty [18] suggest that the strongly inhibited coarsening is in line with theory, in that during the last stages of solidification there will be large scale coalescence of adjacent dendrite arms with the same orientation. This leads to the formation of trapped liquid pockets within the grains, terminating the rapid coarsening. The results for spray-formed Al$4 \mathrm{Cu}$ [28] are more of a puzzle. Fig. 5 shows three sets of results for spray-formed $\mathrm{Al}-4 \mathrm{Cu}$ : those due to Grant et al. [28] (open pink squares); those due to Hee Soo Kim [29] (open blue circles); and those due to Manson-Whitton et al. [19] (open pink triangles). The latter two sets of results both give coarsening rates above the $650 \times 10^{-18} \mathrm{~m}^{3} / \mathrm{s}$ upper bound for Fig. 6 . Annavarapu and Doherty [18] suggest that, in general, spray forming will tend to give low coarsening coefficients because of drag on liquid film migration (at high fractions of solid) by minority second phase particles - solid or gas. Since the alloy for the three sets of results is relatively clean $\mathrm{Al}-4 \mathrm{Cu}$ in each case, this suggests there must be some difference in the spraying conditions which is potentially leading to gas incorporation in the materials for the study reported in [28] in comparison with [29] and [19]. This surmise is supported by private communication [36] which indicates that the material for [28] was prepared in a relatively small sprayforming batch on University scale equipment whereas that for [19,29] was prepared on commercial equipment in a large billet. There are likely to have been differences in the percentage of porosity in the two types of material, with perhaps $1-3 \%$ porosity in the former as opposed to $0.5-1.5 \%$ in the latter.

The SIMA Al-4Cu [33] (solid pink dashes) contains a grain refiner which is likely to give rise to particles which inhibit boundary migration as discussed above. The AlSi7Mg0.6 [27] (solid brown square) is prepared by the SIMA route. Inspection of the composition data shows that it includes $0.13 \mathrm{wt} \%$ Ti which may again be inhibiting boundary migration.

For the results in Fig. 5 which are higher than $650 \times 10^{-18} \mathrm{~m}^{3} / \mathrm{s}$, other than those from $[19,29]$ for spray-formed $\mathrm{Al}-4 \mathrm{Cu}$, two points are for material in this study which does not contain elements likely to form particles inhibiting boundary motion (201 produced with the cooling slope (blue cross) [25 and this work] and 'modified' 2014 which has had all the minority particle forming elements 'stripped out' (open black triangle) [25 and this work]). There are two results from ref [30] which should be compared. The dark blue star is for 6061 prepared 
by the RAP route. This should be compared with the solid green line which is for 6061 which has had the Mn and Cr stripped out. The coarsening coefficient is then significantly higher. Pitts suggests that this is due to the removal of $\mathrm{Mn}$ and $\mathrm{Cr}$ based insoluble intermetallics [30]. Note that the data in [30] has been re-examined for this work and the coarsening coefficient recalculated. The pink cross is for DC cast AlCu4.5Mg1.5 from Annavarapu and Doherty [18] (pink cross). They argue that the relatively high coarsening rate is due to dendrite arm coalescence. The diagonal red cross [35] and solid green circle [34] are both for MHD cast alloys with classic cast compositions. The result for DC cast AlSi7Mg0.6 from Loué and Suery [27] (solid brown diamond) is higher than that for the same material prepared by the SIMA route (solid brown square). Loué and Suery suggest that this is associated with a higher contribution to coarsening from coalescence in the DC cast material. However, there is some evidence that in SIMA material the texture of neighbouring globules is, to some extent, 'inherited' from the same extruded grain (as is demonstrated in [37]) making coalescence relatively easy. This issue is yet to be resolved.

Overall, the range of results for coarsening coefficient can be rationalised essentially in terms of the presence, or otherwise, of agents which are pinning grain boundaries or interfering with diffusion through liquid along grain boundaries. These agents include: insoluble intermetallics based around elements such as $\mathrm{Fe}, \mathrm{Mn}, \mathrm{Cr}$; porosity or; grain refining species such as those based on $\mathrm{Ti}$.

\subsection{The Effects of Liquid Fraction on Coarsening Rate}

Although in this study we have not obtained coarsening coefficients for a range of liquid fractions (there are two liquid fractions for CS 2014 but for the other alloys only one) we will examine here the data from the literature on variation with liquid fraction to check whether our data are consistent with results which have been obtained previously.

Fig. 7 shows the coarsening coefficient (K) vs. fraction liquid, assuming equation (1) applies, for Al-Cu alloys. The data from [19] for spray-formed $\mathrm{Al}-4 \mathrm{Cu}$ show an increase in $\mathrm{K}$ up to about $25 \%$ fraction liquid, followed by a decrease. The other data sets do not cover such a wide range of liquid fractions. The two points from Hee Soo Kim [29] are essentially consistent with the data for low liquid fractions (20\%) from Manson-Whitton et al. [19]. There are two points from Grant et al. [28] which are for low fractions liquid (about 5\% and 
10\%). These show lower coarsening rates than Manson-Whitton et al. [19] and the possible reasons for this, in terms of spray forming conditions, have been discussed above. Data from Ferrante and de Freitas [33] are essentially linear spanning about 15\% fraction liquid through to about $40 \%$. These points are for SIMA Al-4Cu with grain refiner. There is just slight evidence that the points might follow a similar trend to the Manson-Whitton et al. data with a peak around $30 \%$ fraction liquid. The regression coefficient for the linear fit is relatively low at $R^{2}=0.85$. The linear fit is, however, relatively good for the results from Annavarapu and Doherty [18] for Al-6.7Cu. The Manson Whitton et al. theory therefore requires further confirmation by experiments with a wide range of liquid fractions and with materials with varying dihedral angles for liquid in contact with solid.

In Fig. 8, results from this study are plotted alongside results for other wrought alloy compositions (in summary 2014 alloys (spray cast, SIMA, CS), 2618 (spray formed), AA7034 (spray formed)). It is only in the Manson Whitton et al. study for 2618 [19] that there is evidence of a sharp increase in coarsening coefficient between 25 and $30 \%$ liquid. As commented in the Introduction, Manson Whitton et al. account for this by suggesting that, either the particles which are inhibiting boundary movement are dissolving/melting as the temperature increases, or they may be becoming small relative to the thickness of the liquid film. There is some suggestion of non-linear behaviour for the results for spray formed AA7034 [29]. The data from Annavarapu and Doherty [18] for spray cast AA2014 are essentially linear. There are only two points for the CS 2014 from this study and therefore it is difficult to draw conclusions about the effect of liquid fraction variation, although the data are close to those for AA2014 produced by spray casting [18]. The data point from this study for modified 2014 (with elements which might produce pinning intermetallics stripped out) produced with the cooling slope would be off the top of the graph (45\% liquid giving a coarsening coefficient of $\left.2157 \mu \mathrm{m}^{3} / \mathrm{s}\right)$. The result for RAP 2014 from this study $\left(173 \mu \mathrm{m}^{3} / \mathrm{s}\right.$ for $37 \%$ liquid) is close to the Hee Soo Kim results [29] for a different alloy. Again there is a need for further studies at a range of liquid fractions to examine whether the phenomenon of 'unpinning', demonstrated in the Manson-Whitton et al. [19] results at a certain liquid fraction, occurs in other alloys but perhaps at different liquid fractions. It may be that 2014 is much more resistant to such a phenomenon as the Fe based intermetallics are essentially insoluble. If, at high liquid fractions, no such 'unpinning' is observed, this supports the first Manson-Whitton hypothesis (i.e. dissolution/melting of particles in 2618), as the second 
hypothesis (pinning particles becoming small relative to the thickness of the liquid film) would not be alloy sensitive.

\subsection{Implications for Thixoforming}

In thixoforming, material is heated into the semi-solid state and held until an isothermal temperature profile is achieved, before forcing the material into the die. If the coarsening coefficient is relatively high, the time in the semi-solid state must be absolutely minimised in order to avoid coarse microstructures with poor capacity to flow into thin sections (compare particle sizes of 150-200 $\mu \mathrm{m}$ with potential component wall thicknesses of $1 \mathrm{~mm}$ ). In addition, coarse microstructures will tend to have poor mechanical strength. Processing windows may be a little less stringent for the alloys such as those based on the wrought compositions, which give relatively low coarsening rates. However, it should be noted that these alloys are inherently difficult to thixoform for other reasons [24,37].

\section{Conclusions}

Two potential routes to suitable starting material for thixoforming are recrystallisation and partial melting (RAP) and cooling slope (CS). Here the microstructural coarsening of such materials in the semi-solid state has been analysed.

A lower coarsening rate was observed for RAP route 2014 alloy (coarsening rate $\mathrm{K}=173$ $\mu^{3} \mathrm{~s}^{-1}$ at $625^{\circ} \mathrm{C}$ with $37 \%$ fraction liquid) than for CS route 2014 alloy (coarsening rate $\mathrm{K}=192 \mu^{3} \mathrm{~s}^{-1}$ at $610^{\circ} \mathrm{C}$ with $17 \%$ fraction liquid) despite the higher fraction liquid for the former. For the CS route, an increase in fraction liquid gave a higher coarsening rate, (coarsening rate $\mathrm{K}=192 \mu \mathrm{m}^{3} \mathrm{~s}^{-1}$ at $610^{\circ} \mathrm{C}$ with $17 \%$ fraction liquid and $255 \mu^{3} \mathrm{~s}^{-1}$ at $620^{\circ} \mathrm{C}$ with $28 \%$ fraction liquid). A relatively high coarsening rate was observed in a modified 2014 alloy with the Fe, Mn and $\mathrm{Zn}$ stripped out of the composition and a relatively low Si content $\left(\mathrm{K}=2157 \mu \mathrm{m}^{3} \mathrm{~s}^{-1}\right.$ at $631{ }^{\circ} \mathrm{C}$ with $45 \%$ fraction liquid). The coarsening rate was also relatively high for alloy 201 prepared by the CS route $\left(\mathrm{K}=1384 \mu^{3} \mathrm{~s}^{-1}\right.$ at $620^{\circ} \mathrm{C}$ with $20 \%$ fraction liquid) compared with alloy 2014 either by RAP or CS. 
In the literature, dendrite arm coalescence is discussed as potentially contributing to coarsening. Here, this mechanism is having a relatively minor effect after the very initial stages for Cooling Slope material. CS cast 2014 exhibits a lower coarsening rate constant than CS cast modified 2014 and alloy 201. This is attributed to the presence of secondary phases in the 2014, which are pinning the liquid boundary migration. The particles must be resistant to dissolution and are likely to be the insoluble Fe, Mn-based intermetallics. These findings support observations in the literature about the role of second phase particles.

Compilation and analysis of data from the literature further supports the argument that those alloys which give relatively low coarsening coefficients contain agents of some form which will pin the liquid film grain boundaries (insoluble intermetallics based around elements such as $\mathrm{Fe}, \mathrm{Mn}, \mathrm{Cr}$, porosity, grain refining species such as those based on Ti). Thus, wrought alloy compositions tend to give relatively low coarsening coefficients, as do alloys which contain grain refiner.

\section{Acknowledgements}

The authors would like to acknowledge the UK Engineering and Physical Sciences Research Council (EPSRC Grant GR/M89096) and the University of Leicester for financial support. The University of Sheffield provided experimental facilities. Dr Andrew Norman at the University of Leicester is thanked for assistance with diagrams.

\section{References}

1. M. C. Flemings, Metall. Trans. A 22 (1991) 957.

2. D. H. Kirkwood, Int. Mater. Rev. 39 (1994) 173.

3. A. de Figuredo, editor, 'Science and Technology of Semi-Solid Processing' (North American Die Casting Association, Rosemont, IL, 2001).

4. Z. Fan, Int. Mater. Rev. 47 (2002) 49

5. H. V. Atkinson, Prog. Mater. Sci. 50 (2005) 341.

6. D. H. Kirkwood, C. M. Sellars, L. G. Elias Boyed, 'Thixotropic Materials' European Patent No. 0305375 B1, 28 October 1992. 
7. T. Haga, T. Kouda, H. Motoyama, N. Inoue, S. Suzuki, In: Proc ICAA7, Aluminium Alloys: Their Physical and Mechanical Properties, Charlottesville, VA., Part 1 (1998) 327-32, Publ. Trans Tech Publications 2000.

8. T. Kaneuchi, R. Shibata and M. Ozawa, in Proceedings of the $7^{\text {th }}$ International Conference on Advanced Semi-Solid processing of Alloys and Composites, Tsukuba, Japan, 2002, edited by Y. Tsutsui, M. Kiuchi, K. Ichikawa (National Institute of Advanced Science and Technology and the Japan Society for Technology of Plasticity 2002) p.145.

9. A. Mitsuru, S. Hiroto, H. Yasunori, S. Tatsuo, S. Satoru and Y. Atsushi, Method and Apparatus for Shaping Semisolid metals, UBE Industries Limited, Patent EP 0745694 A1 (1996).

10. T. Haga, J. Materials Processing Technol., 130-131 (2002) 558.

11. A. D. Lima Filho and M. I. Yamasaki, Solid State Phenomena, 116-117 (2006) 433.

12. K. P. Young, C. P. Kyonka, J. A. Courtois, "Fine Grained metal composition", US Patent No. 4,415,374, 30 March 1982.

13. T. Y. Liu, H. V. Atkinson, P. Kapranos, D. H. Kirkwood and S. C. Hogg, Metallurgical and Materials Transactions A, 34A (2003) 1545-1554.

14. D-S. Han, I. C. Stone, B. Cantor, in: C. G. Kang, Y. H. Moon (Eds.), Proc of Int. Symp. on Advanced Forming and Die Manufacturing Technology, Korea, Pusan National University, 1999, pp. 65-70.

15. G. W. Greenwood, Acta Metall., 4 (1956) 253.

16. I. M. Lifshitz, V. V. Slyozov, J. Phys. Chem. Solids, 19 (1961) 35.

17. C. Wagner, Z. Electrochemie, 65 (1961) 581.

18. S. Annavarapu and R. D. Doherty, Acta Metall. Mater. 43 (1995) p. 3207-3230.

19. E. D. Manson-Whitton, I. C. Stone, J. R. Jones, P. S. Grant, B. Cantor, Acta Mater. 50 (2002) p.2517-2535. 
20. S. S. Kim, D. N. Yoon, Acta Metall., 31 (1983) 1151.

21. W. J. Boettinger, P. W. Voorhees, R. C. Dobbyn, H. E. Burdette, Metall. Trans., 18A (1987) 487.

22. E. R. de Freitas, E. Ferracini Jr., M. Ferrante, J. Mater. Process. Technol., 146 (2004) 241.

23. E. Tzimas and A. Zavaliangos, Mater. Sci. Eng. A289 (2000) p. 228-240.

24. D. Liu, H. V. Atkinson, P. Kapranos, W. Jirattiticharoean and H. Jones, Mater. Sci. Eng. A361 (2003) p. 213-224.

25. D. Liu, Thixoforming of High Performance Alloys Mainly Based on the Al-Cu System, PhD thesis, University of Sheffield, 2003.

26. E. Cardosa Legoretta, H. V. Atkinson, H. Jones, "Cooling Slope Casting to Obtain Thixotropic Feedstock II: Observations with A356 Alloy" submitted to Journal of Materials Science.

27. W. R. Loue and M. Suery, Mater. Sci. Eng. A203 (1995) p. 1-13.

28. P. S. Grant, R. P. Underhill, W. T. Kim, K. P. Mingard and B. Cantor, in Spray Forming 2 (edited by John V. Wood), p. 45. Woodhead, Cambridge, England (1993).

29. Hee-Soo Kim, PhD thesis, University of Oxford, UK, 2003

30. H.Pitts, Semi-solid Processing of Aluminium 6061, PhD thesis, University of Sheffield, 1999, p.52

31. S.Chayong, Thixoforming Processing of Aluminium 7075 Alloy, $\mathrm{PhD}$ Thesis, University of Sheffield, 2002, p.98

32. L. Salvo, M. Suery, Y. De Charentenay and W. Loue, Proceeding of 4th international conference on semi-solid processing of alloys and composites, Sheffield, UK, June 1921, 1996, p.10-15.

33. M. Ferrante, E. de Freitas, Mater. Sci. Eng. A271 (1999) p. 172-180

34. M. Kiuchi, J. Yanagimoto and S. Sugiyama, Proceeding of 5th international conference on semi-solid processing of alloys and composites, Colorado, USA, June 23-25, 1998, p. 589-596.

35. E. J. Zoqui, M. T. Shehata, M. Paes, V. Kao, E. Es-Sadiqi, Mater. Sci. Eng. A325 (2002) p. 38-53.

36. P. S. Grant, Oxford University, Private Communication, Jan 2008.

37. D. Liu, H. V. Atkinson and R. L. Higginson, Mater. Sci. Eng. A392 (2005) p. 73-80. 
38. D. Liu, H. V. Atkinson and H. Jones, Acta Materialia 53 (2005) p. 3807-3819. 
Table 1. Starting Materials with Wrought and Cast Handbook Values Shown in Bold for Comparison

\begin{tabular}{|c|c|c|c|c|c|c|c|c|c|c|c|}
\hline & & & & & & & & & & Bal. & As-Received \\
\hline \multirow[t]{2}{*}{201} & $4.0-5.2$ & $0.15-0.55$ & $<0.10$ & $<0.15$ & $0.2-0.5$ & - & - & & & Al & \\
\hline & & & & & & & & $0.15-0.35$ & $0.4-1.0$ & & \\
\hline Mod2014 & 3.87 & 0.6 & 0.14 & $<0.01$ & $<0.01$ & $<0.001$ & - & - & & $\mathrm{Al}$ & $\begin{array}{l}\text { Direct Chill cast, } 73 \\
\text { mm diameter }\end{array}$ \\
\hline 2014 & $3.9-5.0$ & $0.2-0.8$ & $0.5-1.2$ & $<0.7$ & 0.4-1.2 & $<0.25$ & $<0.1$ & $<0.15$ & & Al & \\
\hline
\end{tabular}

All compositions are in wt.\%. For experimental materials, the compositions were measured using the Inductively Coupled Plasma Emission Spectroscopy (ICPES) method.

'Mod' refers to 'Modified' Alloys. 
Table 2 Temperatures of Isothermal Holding and Corresponding Liquid Fractions from Fig. 1

\begin{tabular}{|l|l|l|}
\hline Alloy & Isothermal Holding Temperature $\left({ }^{\circ} \mathrm{C}\right)$ & Liquid Fraction $(\%)($ Error $\pm 3 \%)$ \\
\hline Extruded 2014 in T6 heat treatment condition & 625 & 37 \\
\hline $\begin{array}{l}\text { Extruded 2014 in T6 condition and then } \\
\text { cooling slope treated (assuming identical DSC } \\
\text { behaviour to the material above) }\end{array}$ & 610 & 28 \\
\hline Modified 2014 cooling slope treated & 631 & 18 \\
\hline Alloy 201 cooling slope treated & 620 & 45 \\
\hline
\end{tabular}




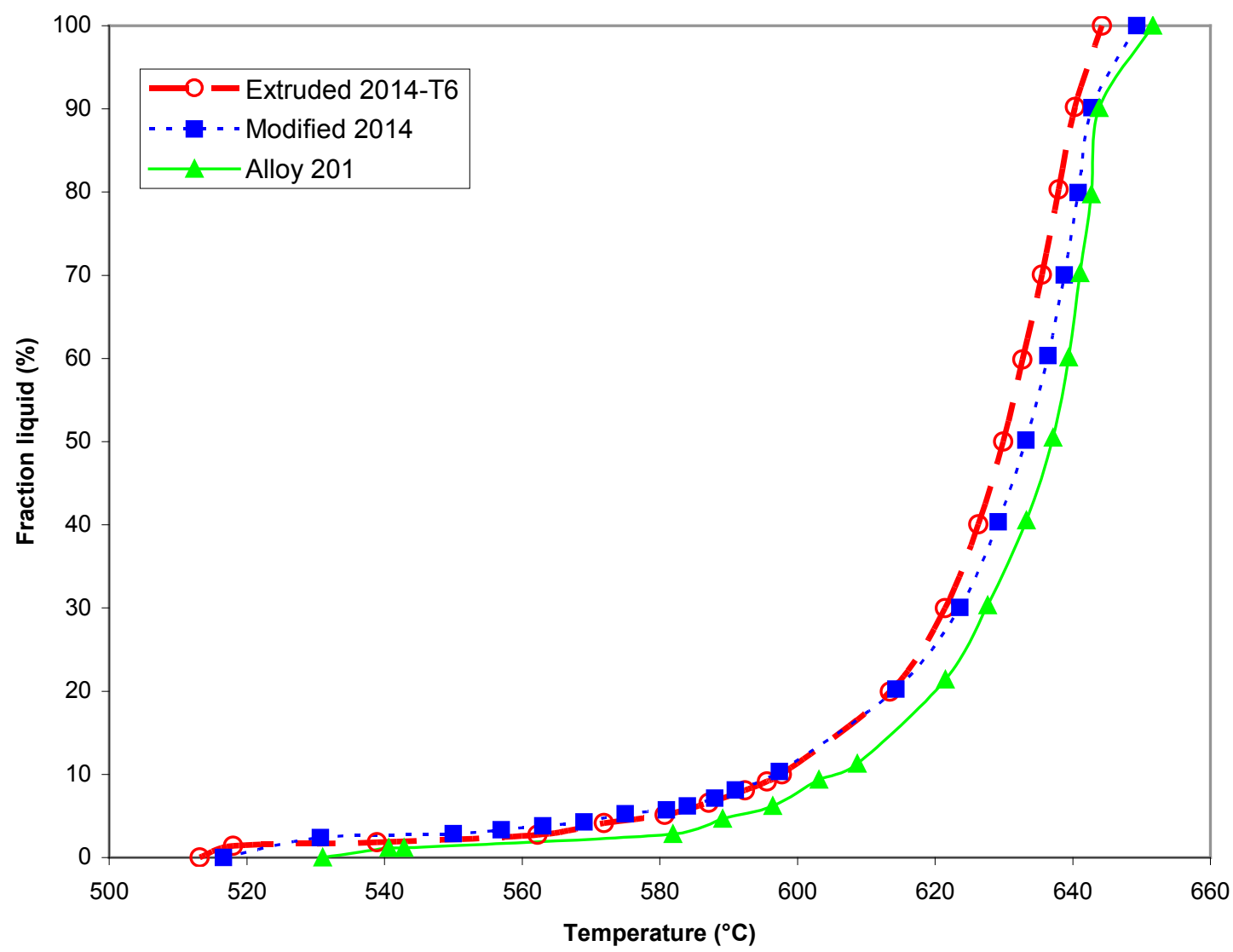

Figure 1 Fraction Liquid vs. temperature estimated from DSC heating curves for different materials 
As cast into steel mould
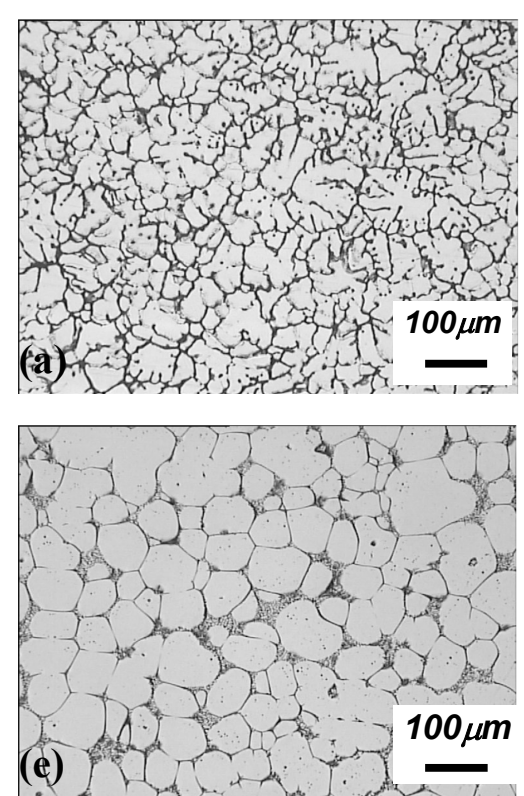

(e)
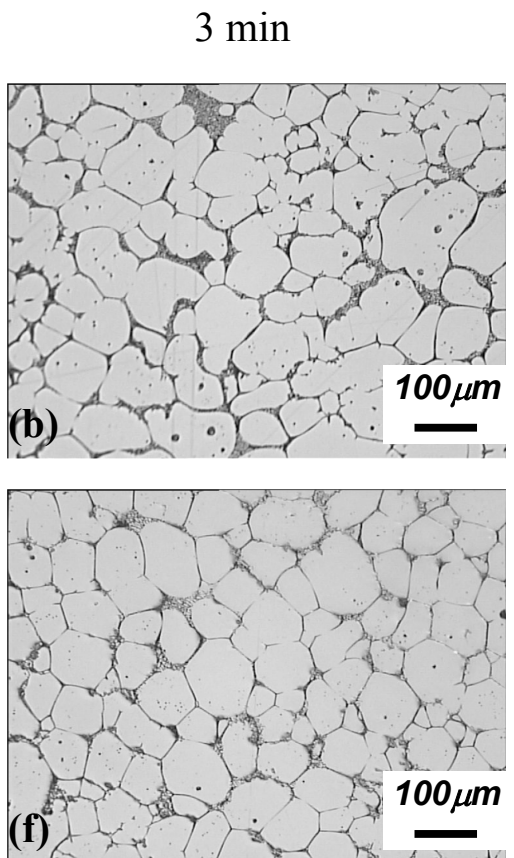

$1 \min$

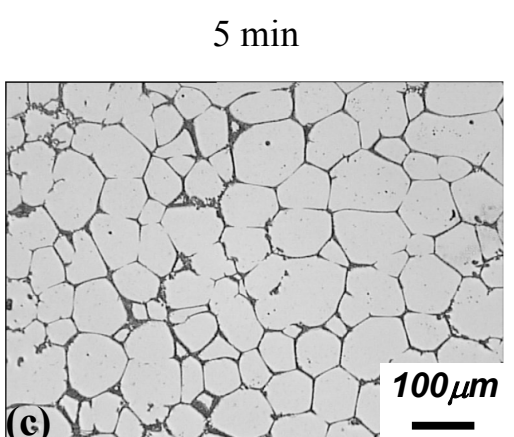

$10 \min$
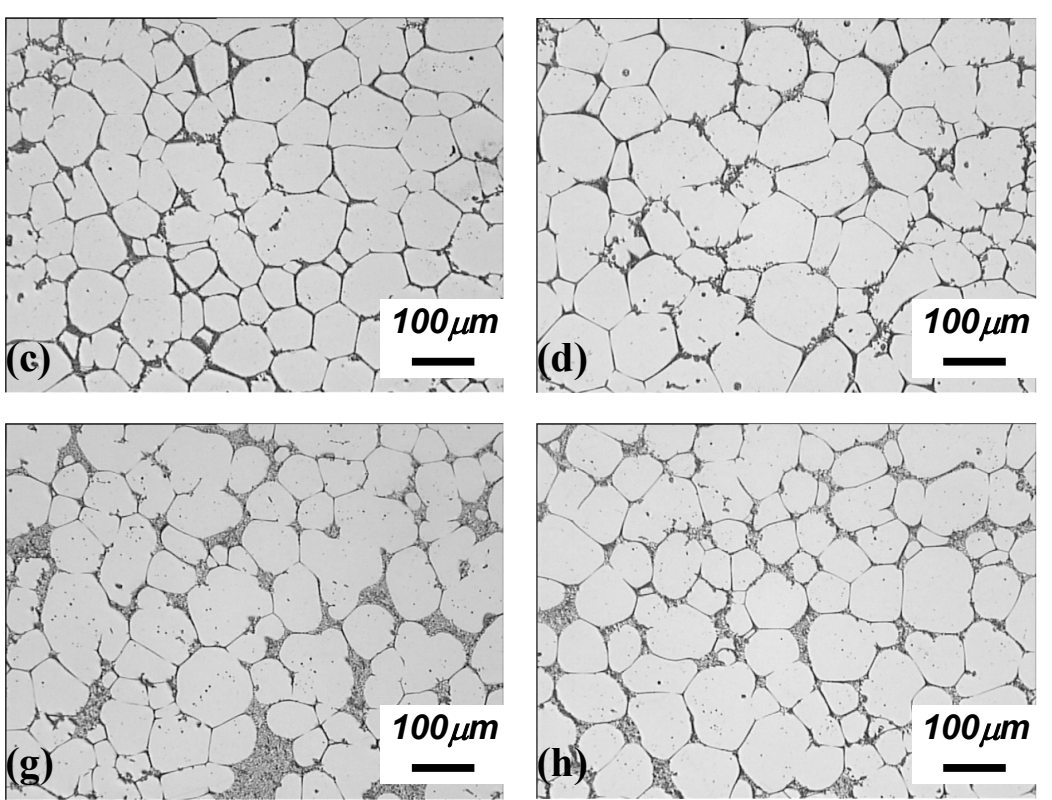

(h)

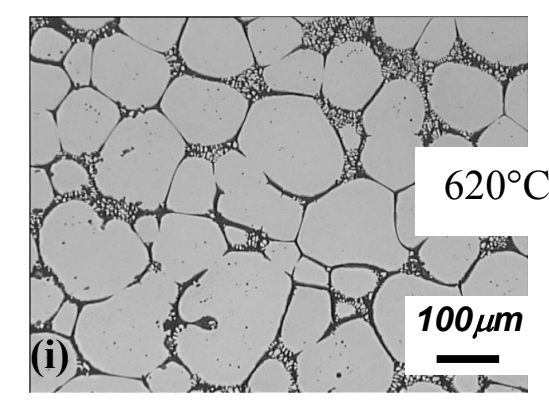

$30 \mathrm{~min}$

Figure 2 Structural evolution of 2014 cast down a cooling slope into a steel mould and then held in the semisolid state in a salt bath either at $610^{\circ} \mathrm{C}$ (top row) or $620^{\circ} \mathrm{C}$ (bottom row):(a) cooling slope cast in steel mould; (b), (c), (d) $3,5,10$ min at $610^{\circ} \mathrm{C}$; (e), (f), (g), (h), (i) $1,3,5,10$, $30 \mathrm{~min}$ at $620^{\circ} \mathrm{C}$ (longitudinal sections). 


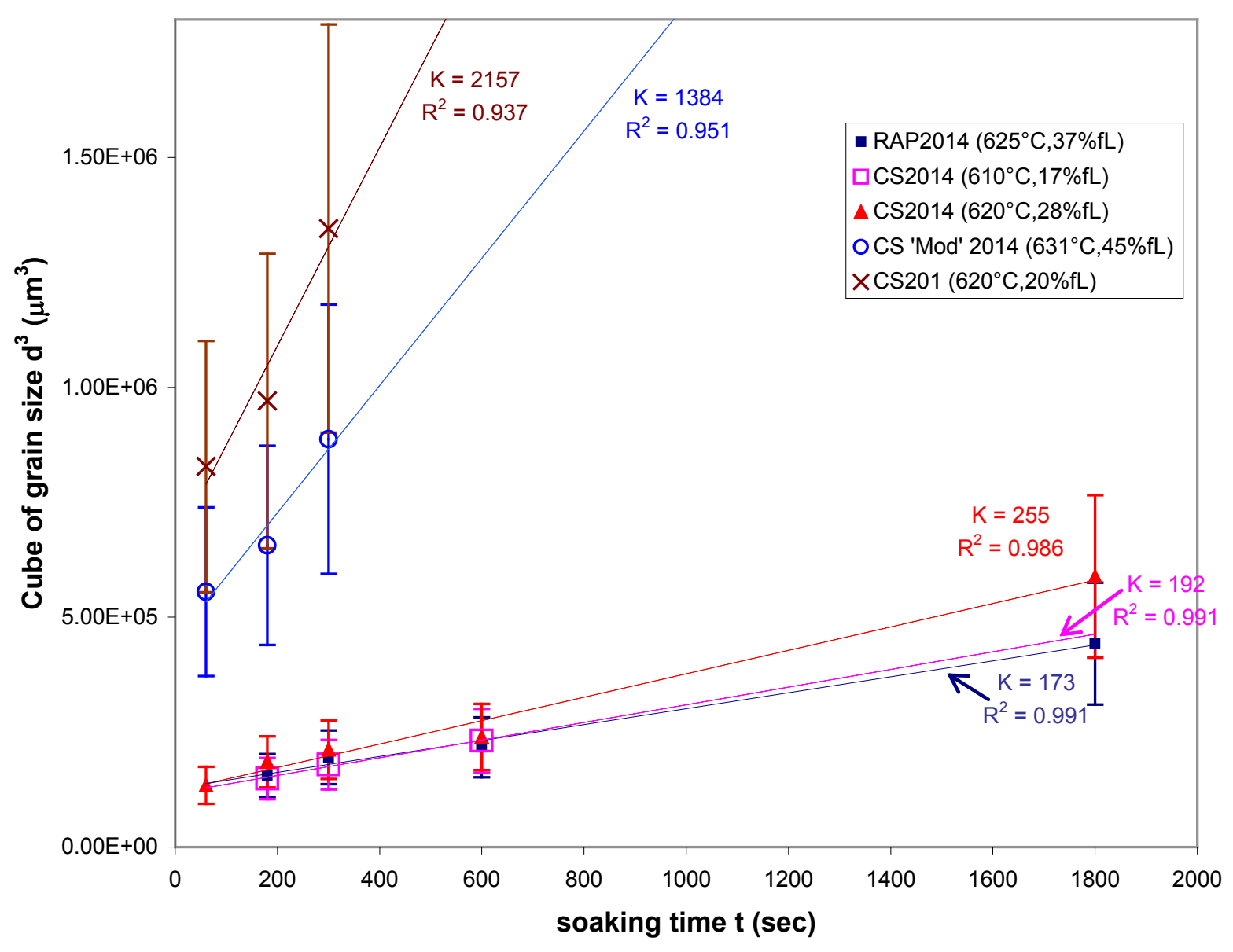

Figure 3 Evolution of the average globule diameter $d$ as a function of isothermal soaking time at 610 to $631^{\circ} \mathrm{C}$ in the semi-solid state for different materials. Dotted lines represent evolution according to $\mathrm{d}^{3}=\mathrm{d}_{0}{ }^{3}+\mathrm{Kt}$. The unit for $\mathrm{K}$ in each case is $\mu \mathrm{m}^{3} \mathrm{~s}^{-1}$. $\mathrm{R}^{2}$ is the regression coefficient. 


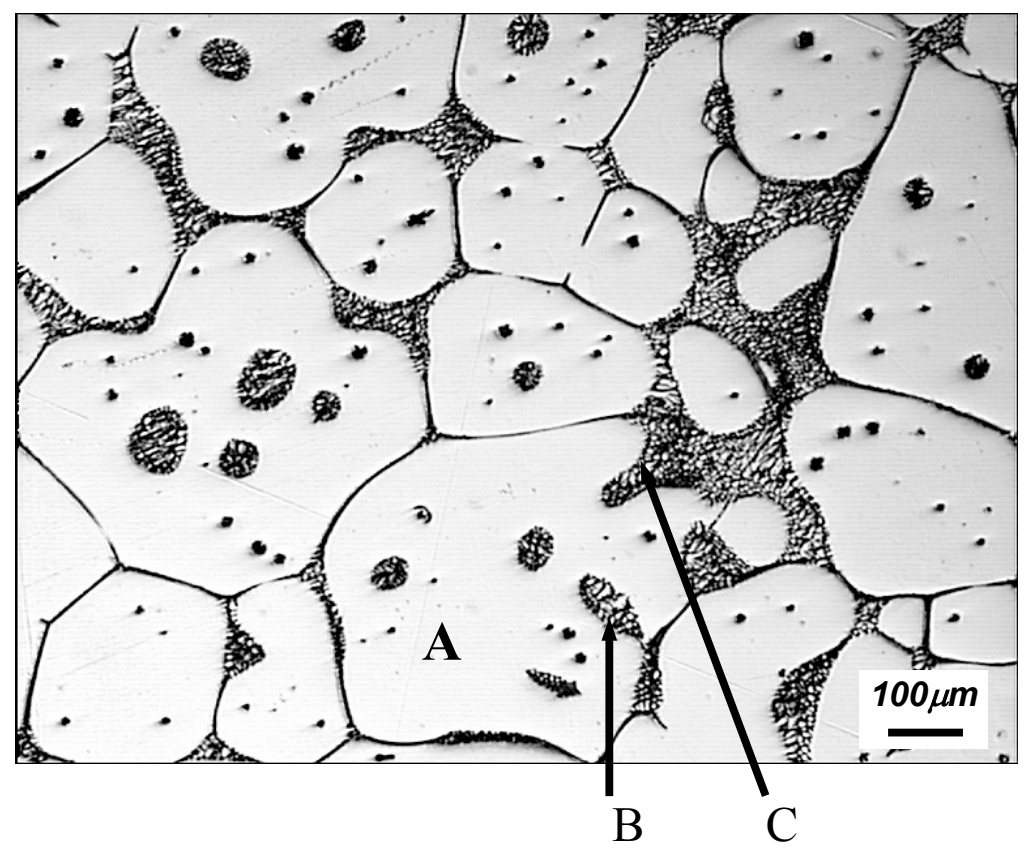

Figure 4 Presence of entrapped liquid in primary grains in cooling slope modified alloy 2014 soaked for $5 \mathrm{~min}$ at $631^{\circ} \mathrm{C}$. 
-AA2014 (spray cast) [18]

$\Delta 2014$ (CS) [25 and this work]

$\triangle \mathrm{Al}-4 \mathrm{Cu}$ (spray formed) [19]

- Al-4Cu (SIMA with grain refinement) [33]

$\Delta$ Mod2014 (CS) [25 and this work]

* A2017 (Shear Cooling Roll) [34]

+ AA2618 (spray formed) [19]

- 6061 without $\mathrm{Mn}$ and $\mathrm{Cr}$ (RAP) [30]

AA7034 (spray formed) [29]

- AICu4.5Mg1.5 (DC-cast with grain refiner) [18]

AISi7Mg0.6 (SIMA) [27]

*AISi7Cu3Mg (MHD cast) [32]
- 2014 (RAP) [25 and this work]

$\square \mathrm{Al}-4 \mathrm{Cu}$ (spray formed) [28]

O Al-4Cu (spray formed) [29]

$\diamond \mathrm{Al}-6.7 \mathrm{Cu}$ (chill-cast) [18]

$\times 201$ (CS) [25 and this work]

2618 (spray formed) [28]

*6061 (RAP) [30-data reexamined for this work]

$\rightarrow 7075$ (RAP) [31]

+AICu4.5Mg1.5 (DC-cast) [18]

AISi7Mg0.6 (DC cast) [27]

$\times A 356$ (MHD cast) [35]

AC7A (MHD cast) [34]

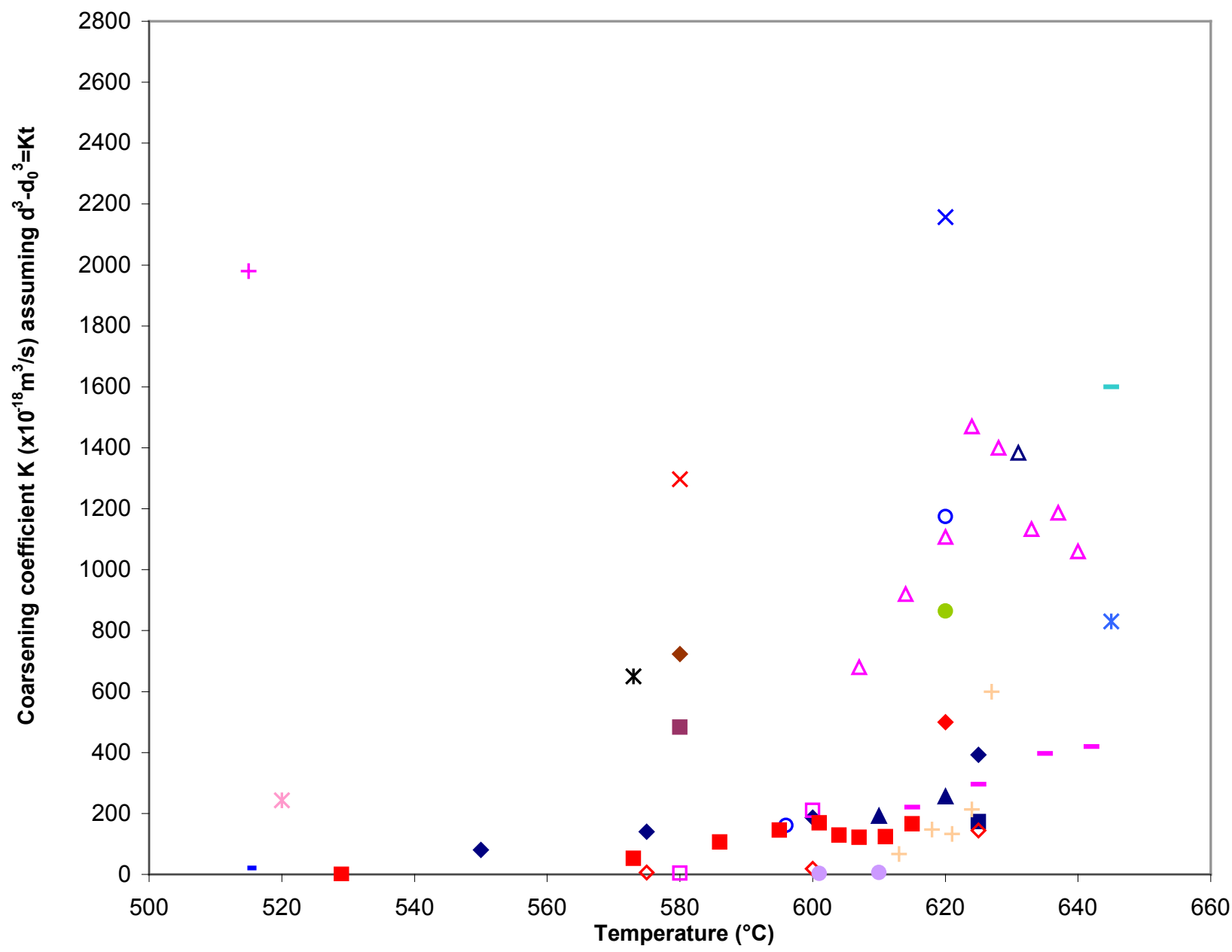

Figure 5 Coarsening coefficient (K) vs. temperature assuming $\mathrm{d}^{3}-\mathrm{d}_{0}{ }^{3}=\mathrm{Kt}$ for $\mathrm{Al}$ alloys showing generally high $\mathrm{K}\left(>600 \mu \mathrm{m}^{3} / \mathrm{s}\right)$ in casting $\mathrm{Al}$ alloys and generally low $\mathrm{K}\left(<600 \mu \mathrm{m}^{3} / \mathrm{s}\right)$ in alloys 
which would normally be wrought. A magnified view for the $0-650 \times 10^{-18} \mathrm{~m}^{3} / \mathrm{s}$ range is shown in Fig. 6.

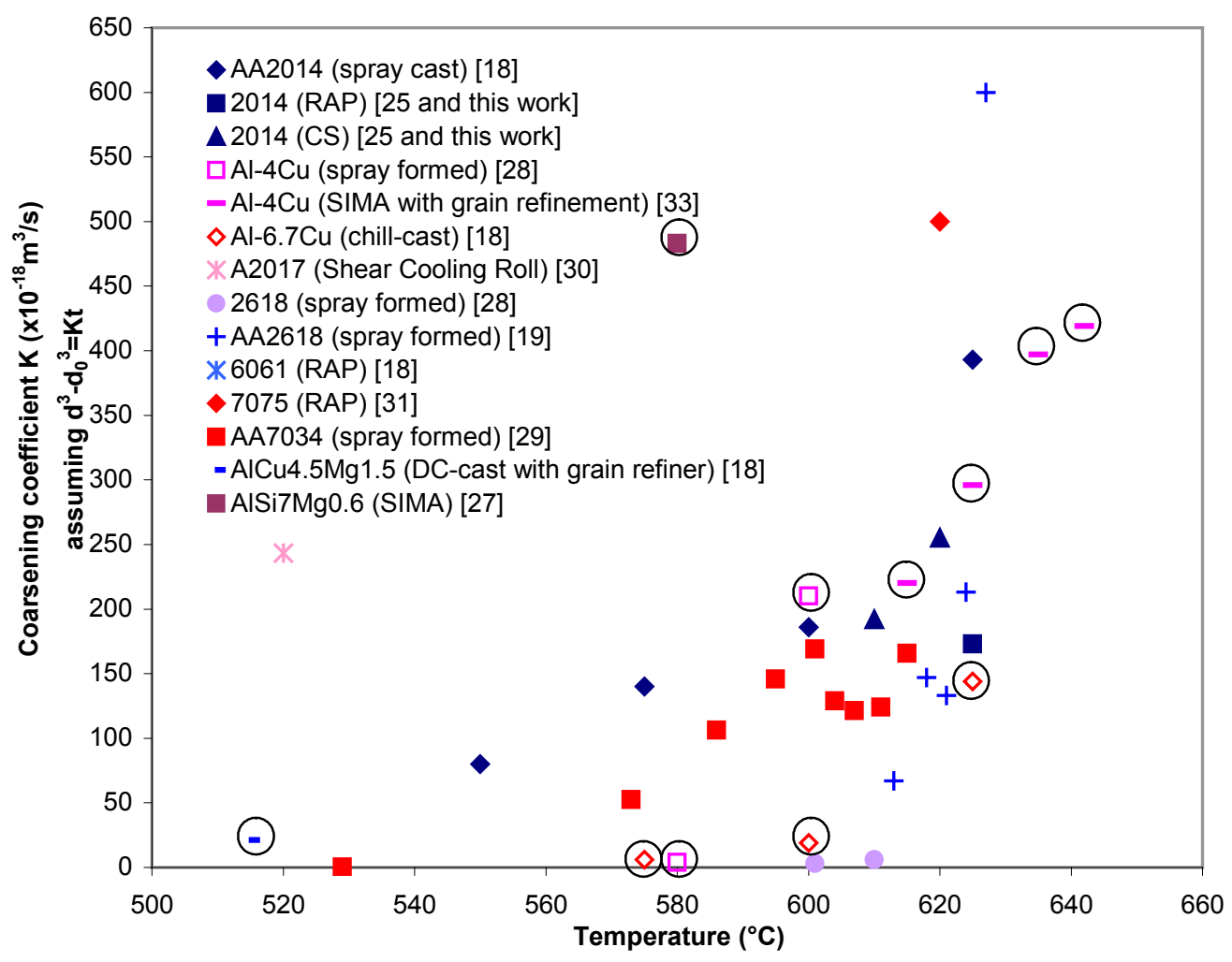

Figure 6 Magnified view of the $0-650 \times 10^{-18} \mathrm{~m}^{3} / \mathrm{s}$ range in $\mathrm{K}$ in Fig. 5. The majority of the results here are for alloys which are normally wrought. A few casting alloys give results in this range and these are circled. These are: grain refined DC-cast $\mathrm{AlCu} 4.5 \mathrm{Mg} 1.5$ [18]; chill-cast Al6.7Cu [18]; spray formed $\mathrm{Al}-4 \mathrm{Cu}$ [28]; SIMA Al-4Cu with grain refiner [33]; and SIMA AlSi7Mg0.6 [27] (all compositions in wt\%). 


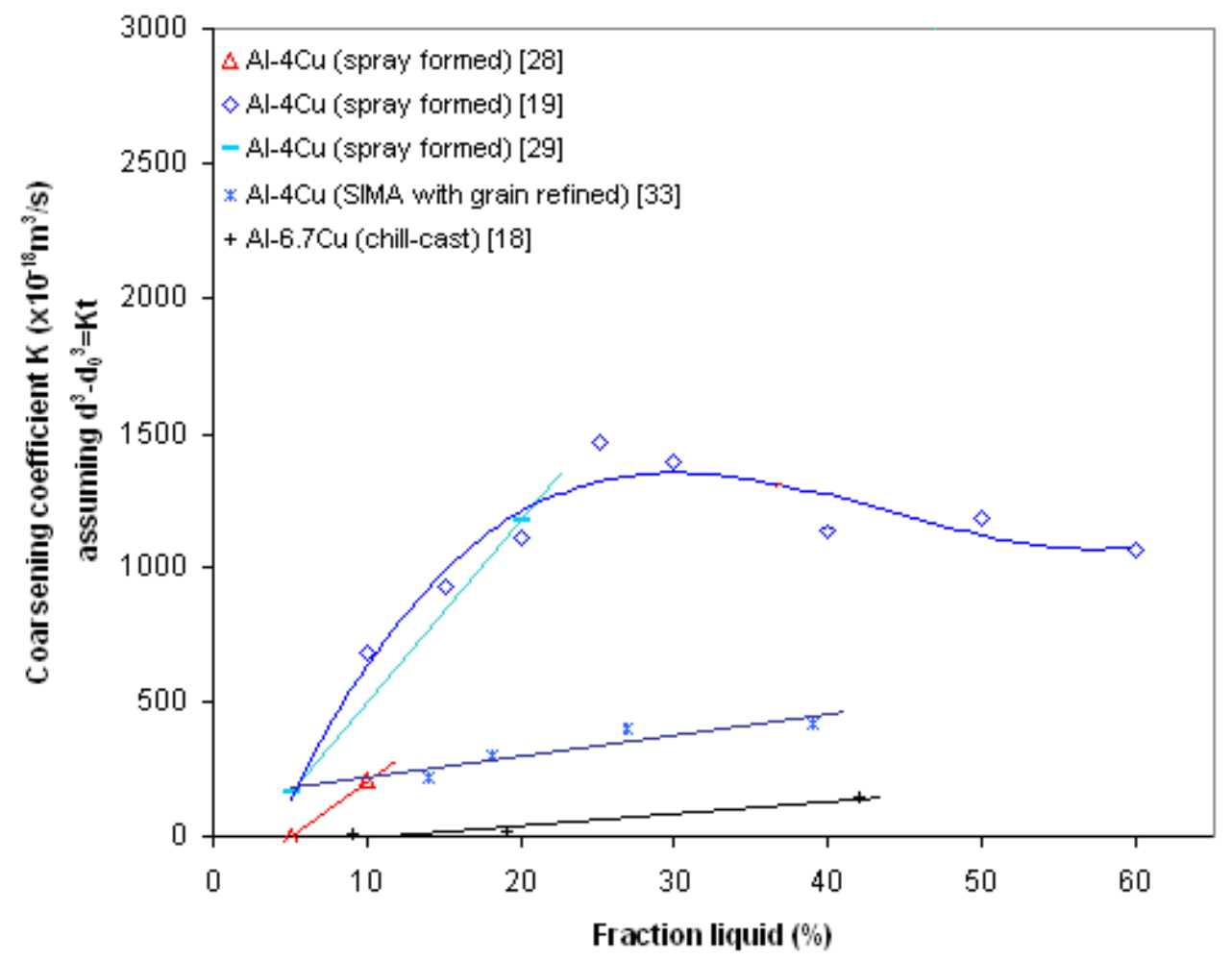

Figure 7 Coarsening coefficient $(\mathrm{K})$ vs. fraction liquid assuming $\mathrm{d}^{3}-\mathrm{d}_{0}{ }^{3}=\mathrm{Kt}$ for $\mathrm{Al}-\mathrm{Cu}$ alloys showing two types of graph: firstly, a linear relationship [28 and 29 over a limited range of liquid fraction, 18 and 33 over a wider range]; secondly, $\mathrm{K}$ increases with increasing fraction liquid and then decreasing after 0.25 fraction liquid [19]. 


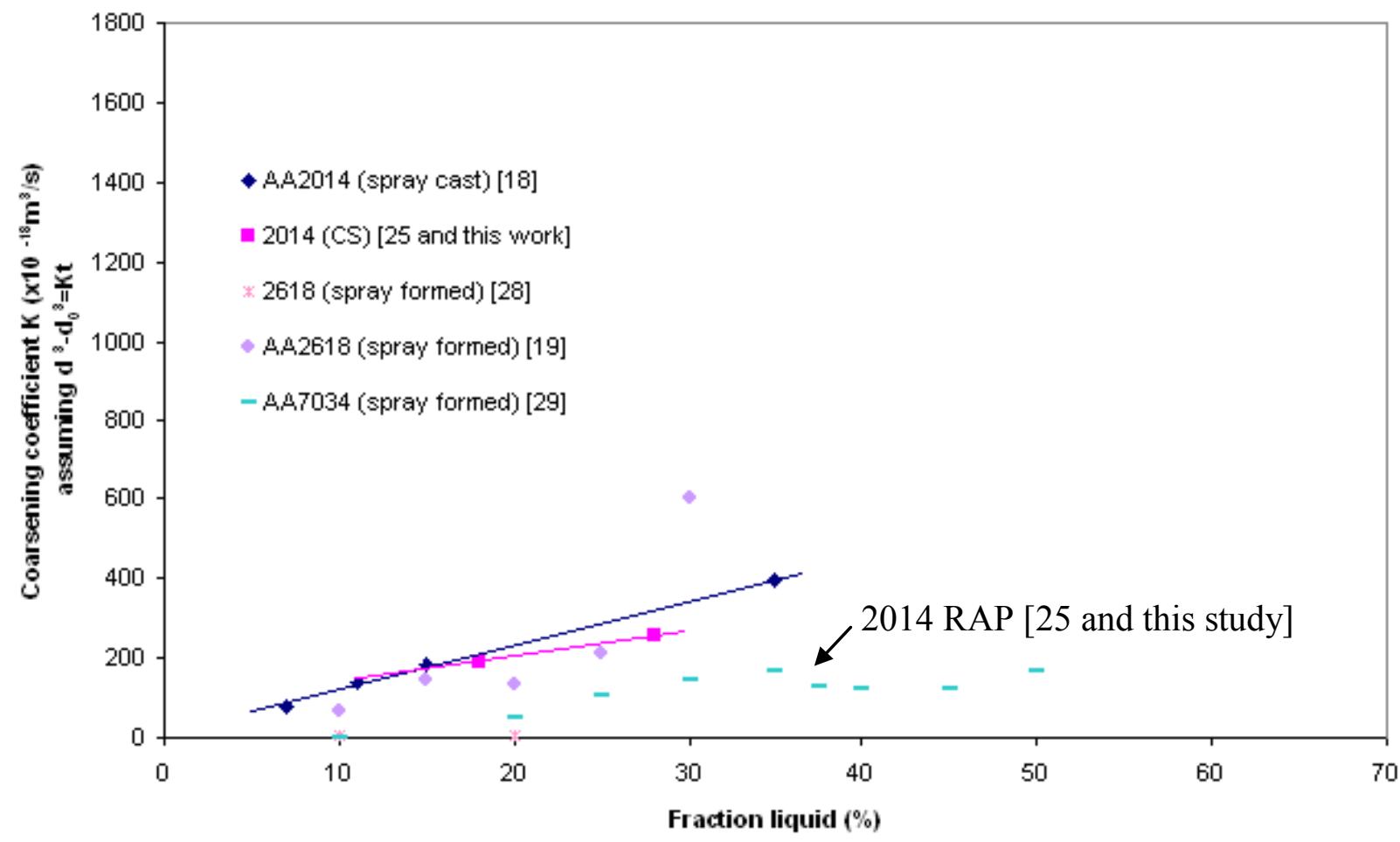

Figure 8 Coarsening coefficient (K) vs. fraction liquid assuming $\mathrm{d}^{3}-\mathrm{d}_{0}{ }^{3}=\mathrm{Kt}$ for wrought composition Al alloys. 
-29 - 